\title{
Creating a shared narrative: the use of causal layered analysis to explore value co- creation in a novel service ecosystem
}

Sanna Ketonen-Oksi®

\begin{abstract}
Purpose: The current business environments are increasingly dominated by the networked and systemic conceptualisation of value creation. However, surprisingly, little is known about the explicit and symbolic (inter) relationships between the different actors involved in the value co-creation processes-or about how they impact on the network-specific innovation capabilities. More research is needed to explore and validate the yet theoretical models and concepts of value co-creation in practice.
\end{abstract}

Design/methodology/approach: Theoretically, this study is built on the ideas and concepts of Service-Dominant (S-D) logic. Empirically, the research is based on a set of thematic interviews conducted in a real-life service ecosystem, in the context of university-industry collaboration. The method of causal layered analysis (CLA) is used to both identify and develop constitutive narratives that support the service ecosystem's long-term strategic planning and value cocreation practices.

Originality/value: The use of CLA in exploring the S-D logical view on value co-creation is a unique combination. By studying a highly social, dynamic and interactive process during which different service ecosystem actors first come together to share their values and mental models, and then act upon, significant new knowledge and understanding is offered for all those interested in applying a more systemic approach on service ecosystem development.

Practical implications: Given that the use of CLA not only increases the awareness of alternative narratives, but of the abilities to facilitate the desired future(s), new insight and practical advice will be provided for both managers and participants taking part in a service ecosystem.

Keywords: Service systems, Service ecosystems, Service-dominant logic, Value co-creation, Causal layered analysis, Futures literacy

\section{Introduction}

The rapid growth of Web 2.0 technologies, particularly social media [1, 2], has fundamentally changed the ways that people interact and communicate with one another [3-5]. While the influence and power of the acquired information and knowledge has considerably decentralised [6], companies have been forced to adopt new, systemic ways to work, socialise and create value $[7,8]$. With a focus on the multi-actor practices, processes and symbols through which various social, economic and technological aspects of change are connected [9-12], it has become

Correspondence: ketonenoksi@icloud.com

Industrial and Information Management, Tampere University of Technology, Korkeakoulunkatu 10, 33720 Tampere, Finland unquestionable to recognise, appreciate, and participate in value co-creation [11].

Besides the more theoretical discussion of value, increasingly dominated by the networked [13-15] and systemic conceptualisation of value creation [16-18], more empirical research is needed to validate the so far developed models and concepts of multi-actor value co-creation in real-life business environments [19, 20]. Except studies focused on organisational learning [21-23] and employee motivation [23] in a variety of socially connected, both internal and external networks [24], little is known about the ways to develop and manage multidimensional networks of actors when loosely coupled in both formalised and nonformalised interactions [25]. Most importantly, more 
knowledge and understanding is needed about the explicit and symbolic (inter)relationships between the different value co-creating actors, often connected to various service systems at the same time $[26,27]$.

The urgent need to support value creation in practice [28] gradually shifts the emphasis on everyday interactions. As companies eventually recognise the strength they have in both individuals and organisations [29, 30], and thus become more aware of their innovation capabilities $[11,31,32]$, they will see themselves as the microcosms of society at large. Eventually, the still dominant firm-centric operations models [11] will be replaced with highly social, dynamic and interactive processes during which different actors come together to share their values and mental models [33]. Considering how difficult it is to break old habits, significant changes are needed to replace the mechanical patterns of thinking with system dynamics [34]. More research is needed to validate the yet theoretical models and concepts of value co-creation practices. Hence, to better understand, how to foster value co-creation in the emerging service ecosystems, the aim of this study was set to explore the explicit and symbolic (inter)relationships between the different actors involved in the value co-creation processes and the ways how they contribute to the network-specific innovation capabilities.

Theoretically, this study is built on the ideas and concepts of Service-Dominant (S-D) logic. In doing so, the term 'service ecosystem' referred to a relatively self-contained, self-adjusting system of resourceintegrating actors or entities which are connected by shared institutional logics and mutual value creation through service exchange [35]. Empirically, this study consists of a set of thematic interviews carried out in the context of university-industry collaboration, that is, in a real-life service ecosystem under construction. Inspired by recent studies indicating that there is a positive consistency between companies' abilities to foster long-term strategic planning and their value co-creation activities [36], and that companies systematically applying corporate foresight outperform their competitors [37], the interviews were analysed with causal layered analysis (CLA), a technique developed for opening up the constitutive discussions among the actors involved in the value co-creation process [38]. While adapting a more systemic and in-depth view on value co-creation, new insight and advice will be provided for those interested in a practice-oriented view on value cocreation in the emerging service ecosystems. By acknowledging the role of knowledge as a key resource for companies to maintain their competitiveness, this study will equally highlight the increased importance of strategic collaboration among education, research and industry [39].

\section{Motivations and theoretical background}

The recent technological breakthroughs have enabled many new patterns and levels of value creation, thus playing a crucial role in transforming how value is being co-created $[4,16]$. Yet, the understanding of the current, technology-driven changes in value creation [40-42] is still rather ambiguous [43]. Considering that 'we live in an anticipatory universe, which is chock-a-block with anticipatory systems and processes' ([29], p. 520), too much attention is still being paid to the ways how to plan, analyse and control the value co-creating processes [36]. In order to systematically relate and combine activities and resources with one another-and thus embrace different forms of collaboration-more focus should be placed on both the individual's and the organisation's abilities to reorient and reframe their thinking around systems, networks and ecosystems [27, 45]. However, when analysing recent literature reviews on the theory of value co-creation, it seems that the current knowledge and understanding about co-creation is surprisingly incoherent and mainly consists of studies on customer experience [19, 20].

Besides understanding the system-level coexistence of structural changes and stability, it is extremely important to recognise the huge differences in how the functioning and the evolution of service ecosystems are being conceptualised, especially depending on the logic being applied. For example, when an organisation succeeds in combining a flexible mind set with a networked and team-based organisational structure, it also supports the abilities of the organisation to implement strategies that embrace foresight and futures literacy [44]. That is, the ability to transform the ways in which value is being created in modern business environments is increasingly connected to the system's ability to engage in cyclic self-renewal and structural coupling where each process of interaction results in the transformation of the system [45].

\section{The S-D logic view of value co-creation and service ecosystems}

In the many firm-centric views on value co-creation, the emphasis lies on the optimisation of monetary wealth for a single actor who takes part in the value exchange [46, 47]. By contrast, the S-D logic view on value creation builds on a socially constructed multi-actor process that occurs at the intersection of activities among providers, consumers or any other possible actors, all of whom are participating in the value co-creation process $[18,19,32]$. In doing so, S-D logic conceptualises value co-creation as something that encompasses many disciplines and perspectives [48-50] and refers to service as the fundamental basis for value co-creation, i.e. as the application of resources (e.g. knowledge and skills) for the benefit of 
others $[47,50,51]$. According to S-D logic, the effectiveness and productivity of an organisation are strongly dependent on both (a) the emergence of variables that make the system more complex and the different contexts where these variables can occur and (b) the relationships among the various independent actors involved in the system [52]. As such, a great majority of the value creation potential is now related to the ways to reconstruct social patterns, i.e. to improve communications and collaboration within and across the different players of the service ecosystems [53].

While the development of service ecosystems is increasingly dependent on the attitudes, skills and practices that embrace collaboration, risk taking and experimentation, i.e. the rules, norms, symbols and other institutional arrangements $[4,41,54]$ that direct the collaborative networks [55], it is particularly important to identify how the different sub-systems each exert on the larger ecosystem. In S-D logical terms, these behaviour and dynamics are explained with the concept of 'service innovation' [56]. While seeing service platforms as a tool to connect the various different actors together and to become interested in value co-creation in the first place, the actual act of value co-creation then happens in a multi-layered process consisting of four major phases of interaction.

First, with co-experience the focus is on reducing the gap between the needs and expectations of the value cocreating actors and in co-defining what individual person or organisations actually mean by service. Second, at codefinition, the actors become aware of each other's capabilities and expectations related to value co-creation. Third, co-elevation is about strengthening the collaboration through high-quality value propositions. Fourth, $\mathrm{CO}^{-}$ development refers to the phase where the co-creation finally becomes true and is being evaluated [56, 57]. By referring to service ecosystems as the structures that support engagement to the process of interaction through knowledge creation and exchange [56,58], the adoption of the $S$-D logical view on service ecosystem thus helps the ecosystem actors to move away from too much planning and control. It helps organisations to better sense the emerging changes in their operational environments and to systematically relate and combine activities and resources with one another [27].

\section{Case study}

Although notable benefits have already resulted from the already-existing knowledge transfer between universities and their industry partners [58], the number of failed attempts to collaborate is also significant [59]. While most of the existing research on university-industry collaborations has been conducted in the USA [60], more research and understanding is needed about how to successfully bridge the cultural, social and political divide between academia and industry [39]. Yet, the current networks tend to focus on data collection rather than on the ways to influence on the strategies and decision-making in more sensitive and fundamental ways [61]. Given the growing interest on both value co-creation and the importance of strategic collaboration among education, research and industry $[38,39]$, more depth and diversity are needed to intensify universities' role in the service economy.

To thus explore and validate the yet theoretical models and concepts of S-D logical value co-creation in practice, an empirical case study was conducted in Tampere, Finland. Besides Finland's consistent position as one of the best education systems in the world [62], the Tampere University of Technology has been ranked as one of the world's leading universities with a large volume of successful industry collaborations [63]. That being the case, this case study offers plenty of opportunities for observing the strategic, operational and transactional relationships within the context of university-industry collaborations [64]: When intertwined and associated with each other, individual institutions may form strong assemblages of institutional arrangements [17] where managing change is not easy. In addition to understanding the context-specific variables that make the system complex [51], it is equally important to succeed in introducing novel concepts and forms that support the multi-actor collaboration. In this particular study, the focus will be on examining the ways to establish sustainable, user-driven and collaborative networks that enhance innovations [65].

\section{Kampusareena-the setting up of a 'real-life' service ecosystem}

Located at the heart of the Tampere University of Technology's campus in Tampere, the Kampusareena building and concept was purposefully designed to encourage and support productive collaborations between the university and a number of its stakeholder organisations. Officially launched in September 2015, the planning and construction work was managed by the University Properties of Finland, a limited company with its core business in producing, maintaining and developing premises for universities, colleges and their partners. Centred in an international community of over 8000 undergraduate or postgraduate students in technology and architecture and home to 1700 employees, Kampusareena offers working spaces for about 100 private companies and public organisations, as well as for about 200 university students and staff members. About half of Kampusareena's premises are occupied by the Tampere University of Technology, and another half is owned by the University Properties of Finland. While the university premises include a scientific library, technical test laboratories, a cafeteria and various student services and services for further education, the University Properties of Finland 
rents its premises to companies and street-level service providers (including a restaurant and a barber).

The Kampusareena premises offer a broad range of services and multipurpose facilities for learning and innovation for both the scientific and business communities. With the slogan 'a hub of science, research and technology' [64], its ambitious objective is to become the centre of a real-life service ecosystem that fosters productive university-industry collaboration. In fact, there are several hubs within the hub itself, including the Kampusklubi co-creation hub run by the University Properties of Finland and the Smart Machines and Manufacturing Competence Centre (SMACC) run together by the Tampere University of Technology and the VTT Technical Research Centre of Finland, as well as the Design for Value (DIMECC D4V) run by DIMECC, Finland's leading industrial co-creation ecosystem. The DIMECC network alone consists of over 2000 research, development and innovation professionals and of more than 400 organisations. The many networking opportunities and concrete forms of cooperation being acknowledged, Kampusareena refers to its role as a platform of engagement that is intentionally designed for the co-creation of shared value [11].

\section{Methods and data}

A set of thematic interviews were carried out within Kampusareena. Instead of studying different contextspecific variables that make a system complex [51], or examining the value networks between the various actors taking part in the ecosystem [65], the focus of this study was to explore and critique the various stories the ecosystem actors present about the evolution of their value co-creation aims and activities. In doing so, the method of CLA was used to shed light on the multiplicity of institutional arrangements $[17,66]$ that drive change and innovation in the studied service ecosystem.

\section{CLA - a method for creating a shared narrative}

Originally developed in the 1990 s by a futures researcher, Sohail Inayatullah, the causal layered analysis (CLA) represents a modern approach to examine the in-depth aspects of social and strategic change $[67,68]$. According to CLA, just as language does not only describe reality constitutes it, metaphors do not only describe, but they also shape and create organisational strategies [69]. By unveiling the different ideological, value-based mind sets of the studied individuals, teams and/or organisations, CLA emphasises the importance of understanding reality through different layers of knowing and observing things. These layers are (1) litany, which refers to issues that are often collectively shared as 'facts' yet rarely questioned or confirmed with real data; (2) social causes, which focus on the system's perspective on economic, social, political and cultural factors and thus explains the behavioural rules behind the litany; (3) discourse, which reveals the significant impact that our historical, social and spatial settings have on our common sense and thinking, including how we build structures and discourses around our values and worldviews; and (4) metaphors and myths, which expose us to narratives and false information that we use to justify ourselves to our inner selves [67-69].

From a theoretical point of view, CLA combines and integrates empirical, interpretative and critical research traditions with practical tools, such as emerging issues analysis, scenarios and back casting. It opens up both past and present value-creating practices and thus unveils any conscious and subconscious preconceptions and perceptions related to the issues being studied. That is, it exposes any tensions, contradictions and vagueness between the collective discourses being represented and internalised [67, 70]. By mapping the narratives, CLA by no means predicts the future, but it helps in creating 'transformative spaces' for alternative futures $[68,70]$. In other words, CLA does not take a stand on whether the stories are true or false; rather, it challenges underlying assumptions about reality and thus facilitates the creation of desired futures [69].

While helping to link empirical findings within the studied sociocultural contexts, CLA provides a concrete tool for constructing and reconstructing powerful stories that (a) make us conscious about the deeper layers of reality and (b) make use of them in more explicit ways. Hence, the systemic use of CLA helps to understand the impact of present actions on the desired systemic changes in social systems and structures. Then, considering that the core narrative can be changed only through adopting new worldviews and values, it highlights the need for constructing narratives that engage people in shared objectives and goals $[38,67]$. This consistency between the four layers is rather uniform with the concept of 'institutional arrangements' used in S-D logic [71]. Hence, given the objective of this study, CLA represents an excellent method for obtaining an in-depth understanding of the interviewees' different social, cultural and behavioural attitudes towards co-creation in the service ecosystem under investigation. In doing so, it also helps to create alternative views for value co-creation between the various actors and actor networks [70, 72]. Moreover, the multilayer analysis will provide explanations about the constitutive discourses at different types and levels of service ecosystems.

\section{Data collection}

The actual data consists of 21 thematic interviews, carried out with 22 individuals. At the time of the interviews, Kampusareena was celebrating its first year of existence. As we can see from Table 1, half (11) of the interviewees were employed by a public organisation, including 
Table 1 Interviewee characteristics

\begin{tabular}{lllll}
\hline & Public organisations & TUT only & Companies & UPF only \\
\hline Number of interviewees altogether & 11 & 7 & 11 & 5 \\
Position in top/middle management & 3 & 4 & 2 & 5 \\
Position as an expert/researcher & 4 & 1 & 6 & 3 \\
Active participation in the concept development & 3 & 4 & 6 & 4 \\
Expertise in innovation research and development & 8 & 1 & 5 \\
Office (mainly) at Kampusareena & 2 & 5 & 3 \\
Active in co-creation at Kampusklubi & 7 & & 5
\end{tabular}

representatives from the Tampere University of Technology (7). The other half (11) of the interviewees represented companies, including University Properties of Finland (5). Or, half of the interviewees represented the two organisations that co-manage the ecosystem, and the other half represented their various stakeholders, including both companies (6) and public, non-profit organisations (4). Importantly, almost half of the interviewees (9) were top- or middle-level managers, with more than half (14) of them being experts in the field of innovation research and development. Again, half of the interviewees had substantially participated in the Kampusareena concept development.

The length of the interviews was about 50 to $60 \mathrm{~min}$ on average. The majority of them (i.e., 18 interviews with 19 individuals) were conducted face to face, whereas 2 of them were made by telephone and 1 over Skype. A set of rather pragmatic questions was prepared to support the quality and conformity of the interviews. Yet, some variations occurred between the individual interviews, mostly due to different levels of expertise or the familiarity with the actual co-creation activities within Kampusareena. Once the data were transcribed, they were stored and organised using NVivo, an Internet-based qualitative data analysis software.

As we can see from Table 2, each of the four layers of CLA were first amalgamated with the four phases of the value co-creation process and then applied according to the research questions specifically designed for each layer: Whereas the first layer (i.e. litany) was built around the interviewees' current perceptions about the platform functionalities, and the second layer (i.e. social causes) described the system-level behaviour and rules that direct the ecosystem development, the third layer (i. e. discourse) collected the worldviews and values with (hidden) impacts on the interviewees' attitudes and behaviour towards value co-creation. Finally, the fourth layer (i.e., metaphors and myths) unveiled the mind sets and concepts that direct the service ecosystem development in reality. Altogether, these four layers of CLA were used to acknowledge possible changes in planning, implementing and creating change within the service ecosystem.

\section{Results}

In general, all the interviewees had very positive attitudes towards Kampusareena and its development. However, as we can see from Tables 3, 4 and 5, some significant differences of opinions and experiences did also occur between the different interviewees. To demonstrate the differences, a variety of direct citations from the interviews will be provided in the tables. Each citation is individually numbered, and for example, 'I-1' refers to 'Interviewee number 1'.

\section{Layer 1: Current perceptions about how the platform supports value co-creation}

For most of the interviewees, Kampusareena represented the most recent development of the high level of universityindustry collaboration between the Finnish universities and companies. As we can see from Table 3, the most positive responses were related to the award-winning architecture and attractiveness of the Kampusareena building, thus emphasising its high brand value for Kampusareena as a

Table 2 Research questions

\begin{tabular}{|c|c|c|c|}
\hline & $\begin{array}{l}\text { CLA, the } \\
\text { four layers }\end{array}$ & $\begin{array}{l}\text { The four phases of the } \\
\text { value co-creation process }\end{array}$ & Research questions \\
\hline 1. & Litany & Co-experience & How do the platform functionalities and location support value co-creation? \\
\hline 2. & Social causes & Co-definition & What are the system-level behaviours and rules that direct the service ecosystem development? \\
\hline 3. & Discourse & Co-elevation & What are the values and worldviews that drive forward the service ecosystem level collaboration? \\
\hline 4. & $\begin{array}{l}\text { Metaphors } \\
\text { and myths }\end{array}$ & Co-development & What are the underlying mind sets and concepts that direct the service ecosystem development in reality? \\
\hline
\end{tabular}


Table 3 Results, Layer 1

Current perceptions about how the platform supports value co-creation

'Finland has some of the best universities in the world as per the their activeness in university-industry collaboration.' (I-7)

The image connected with the platform supports value co-creating activities.' (I-3)

'The idea was to create a landmark, a building that would strengthen the university's brand image.' (I-5)

This concept is interesting. More importantly, the constant competition between the two foundation-based Finnish universities guarantees that the progress will not end here.' (I-1)

Positive feedback confronts scepticism

The physical space is attractive, with an emphasis on the experience [of collaboration].' (I-20)

The location is good. The place has good vibes, and it's crowded there.' (I-11)

'There's too little bustle, and the lobby is nothing but a transit zone.' $(\mid-12)$

'Co-creation is a common topic of discussions, but [it is] not realised in practice. (I-13)

'The resistance for this platform is harsh.' (I-4/16)

Too much attention is given to how things work from the companies' perspectives.' (I-15)

Open versus a closed system

'This place represents a no man's land that is easily accessible to all kinds of actors.' (I-19)

'Ultimately, this place is rather closed. People do not come this far from downtown.' (I-12)

'Even the smallest things can make big barriers for collaboration. The need for a pass [for entering company premises] challenges the concept for open collaboration.' (I-14)

'It is not easy for companies and students to come together. Besides the lobby, there are no places for social encounters.' (I-15)

'All the action happens at the 2nd floor. I barely ever go to any other floor.' (I-4)

'There are challenges in information sharing.' (I-14)

Awareness of the platform

I guess there are quite many people from the university who have never been to Kampusareena.' (I-15)

'It takes time before people get familiar with new concepts.' (I-21/22)

'More effort is needed to encourage dialogue between the different organisations. I don't actually even know the actors there.' (I-20)

'I have not seen changes in the work cultures. At least not yet.' (I-2)

platform for value co-creation. In addition, the central location and the proximity to many other industry partners in the area, as well as the generally positive stance for working at and visiting Kampusareena, were equally appreciated. Yet, the positive overall assessment was also more or less confronted with scepticism and dissatisfaction.

Two particular challenges were brought up: First, even if Kampusareena was considered as an agreeable place to work, the value co-creating effects of the platform were
Table 4 Results, Layer 2

Co-defining the system-level behaviours and rules that direct the ecosystem development

Attitudes towards collaboration and engagement

We will create a new concept where a low threshold results in increased networking and a sense of community.' (I-1)

'Well, this place is good for those who are looking for multidisciplinary collaborations.' (I-5).

'It would be more effective and interesting to have events for dedicated fields of study.' (I-14)

'This platform represents the ongoing change in work cultures.' (I-17)

This platform works for proactive people.' (I-16)

'We believe this platform will be beneficial for us in the long run. Measuring the benefits, however, is difficult.' (I-21/22)

Those who work here in research and teaching - they should be more active.' (I-3)

The aim was to attract companies to join the campus, and to then encourage them to renew their thinking in close collaboration with the university.' (I-5)

'I hope that the platform creates things that companies cannot solve by themselves.' (1-8)

Lack of experimentation

'No big investments are needed. This place could serve as a great platform for testing new tools and methods.' (I-13)

'This platform has a lot of potential as a place for demos.' (I-7)

II wish this platform would encourage taking time for creating something new instead of being effective all the time.' (I-1)

'Allocating more time for the platform activities would certainly be beneficial.' (I-11)

Facilitation requested

'If the aim is to really mix people and ideas, more support is needed to activate the co-creation processes.' (I-20)

The platform owners should take more responsibility for facilitation. They know their own world, but as everything is new to us, we do not know how to navigate there. Channel management [for new platform actors] is needed.' (I-12)

'It is not something that can be automated, I mean, enhancing value co-creation needs coaching and looking after.' (I-8)

'Guidance from a person to a person is a prerequisite for this platform.' (I-13)

(Mis)interpreting the concept

'There's a lot of talk about innovation ecosystems and networking, but I haven't figured out what it could mean for us.' (I-11)

The vision is not clear to all of us. There are many simultaneous processes going on.' (I-16)

The co-creation practices are fragmented, and their interrelations are not obvious.' (I-8)

'[lt seems to me that] either the organisations have not understood the concept [of Kampusareena], or then they have difficulties in creating contents that support the concept.' (I-8)

regarded as rather limited. While the cafeteria was considered as too crowded and noisy, there were not enough spaces for random social encounters. More importantly, most of the activities, including in the different actor- or 
Table 5 Results, Layer 3

Co-elevation of the worldviews and values with (hidden) impacts on attitudes and behaviour

\footnotetext{
Pioneers in university-industry collaboration

This is a laboratory where scientific knowledge about learning and innovation is being applied in practice.' (I-7)

'Given the resources we have in Finland, with not much money and with challenging weather conditions and all, it is important that the Finnish universities stay strong in university-industry collaboration.' $(\mid-1)$

This is a pilot. We kind of open up this campus through integrating it with the city around it.' (I-5)

'Compared to the USA or UK, this is a world-class project.' (I-9)

A showroom versus shared processes
}

We now have a space where our team can meet, which also serves as a showcase toward the outer world.' (I-6)

'We aim to develop operations models that are based on co-creation. This place has an image that supports the aim.' (I-3)

'The real things will not be shared. They are kept in secret to make financial profit. That is my view on how things work.' (I-2)

'Openness is important. There is no point to compete.' (I-10)

'Kampusareena is a platform, and it is the people who co-create.' (I-4)

Ecosystem development takes time

'It is interesting to see how this platform develops and what keeps us here in the long run.' (I-11)

The infrastructure suits co-creation well, but developing the concept takes at least a few years.' (I-10)

'A year is far too short of a time period to estimate the results and success of this platform. Ten years is a minimum.' (I-9)

'It is rather short-sighted to talk so much about financial challenges when this place is meant for creating solutions.' (I-2)

Old habits die hard

'Building up new operations models will take years.' (I-8)

II ICT and electronics, the tradition and culture for co-creation is surprisingly weak.' (I-1)

'The university could be more active in bringing forth their knowledge and supplies.' (I-11)

'Well, we have people here who only work together with the universities or with the companies.' (I-10)

'There is bustle, but no dialogue.' (I-4)

This is a place where university staff is not making science or teaching. For the university, it represents lost resources.' (I-7)

'More information is needed about how to integrate co-creation in the university's scientific research.' (1-3)

'Besides being challenged by the university's ability for quick responses, companies find it difficult to get information about the possibilities for collaboration.' (I-10)

'The goals should be set higher.' (I-2)

Platform-specific facilitation and marketing

It is strategically important that the campus welcomes different actors to work in the same premises. However, this platform is just one of the facilities where that collaboration takes place.' (I-21/22)

'What is needed is events and continuous activities; that is, facilitation.' (I-5)
Table 5 Results, Layer 3 (Continued)

Co-elevation of the worldviews and values with (hidden) impacts on attitudes and behaviour

'It is important that the platform becomes more self-organising in a few years' time.' (I-16)

'There are some tensions between the two managing organisations.' $(\mathrm{I}-16)$

'The role of the university's partnerships unit is not clear to me.' (I-6)

'As I see it, the concept idea is being lost or set aside on purpose. The focus seems to be on short-term monetary profits.' (I-4)

There is an urgent need for a marketing plan including all the main actors of the platform.' (I-12)

'It is not the customers' role to find their way to the services.' (1-10)

'The success stories should be highlighted more, serving as examples.' $(1-2)$

theme-specific hubs located at the Kampusareena premises, were not freely accessible and thus prevented many potential initiatives for resource exchange. The interviewees felt that it was difficult to exchange ideas without prescheduled meetings, thus referring to a rather company-focused and controlled approach to collaboration. Second, most of the interviewees reported challenges in creating or confirming value networks and partnerships with the actors already present at the platform, or with the university staff and students overall. According to the interviewees, the common awareness of Kampusareena was surprisingly weak or out of date, resulting in low levels of participation in the events and other activities taking place at the platform. In short, the interviewees were pleased with the overall atmosphere at Kampusareena, but fairly critical about its success in initiating new resource-integrating connections. Or, the value propositions offered by Kampusareena were not expressed clearly enough.

A certain disequilibrium was noted between the high expectations and the realisation to date of the value cocreation activities (and benefits). On the one hand, Kampusareena was seen as an important landmark and a flagship for both the university and the entire economic region. On the other hand, significant frustrations were brewing underneath the seemingly positive attitude towards co-experiencing the platform and its further development.

\section{Layer 2: Co-defining the system-level behaviours and rules that direct the ecosystem development}

At layer 2 (see Table 4), the benefits of a multidimensional service ecosystem were not well acknowledged. According to several interviewees, there was too much diversity among actors in the ecosystem, thus resulting in fewer noteworthy opportunities for collaboration. As they saw it, the best opportunities for collaboration were based on networks with substance-related interests. 
Surprisingly, many of the interviewees were seemingly satisfied if they met their old friends, colleagues and coworkers at Kampusareena-but they dismissed the value of spending time at events connecting people from different fields of expertise. With some inconsistency in their opinions, most of the interviewees believed that the platform-level success was relying on its ability to foster change in work cultures and to solve complex, multidisciplinary problems. Yet, despite highlighting the platform's potential for serving as a stepping stone for testing various kinds of new ideas, concepts and methods, the collaboration was still focused on rather conventional and simple forms of student assignments or on well-trodden networks of expertise.

Altogether, the concept of value co-creation seemed to be rather narrowly understood. As stated in one of the interviews, too much focus was given to easily measurable projects with short-term benefits. For example, in some cases, the interviewees were genuinely wondering how they could benefit from the value networks and new innovation practices in their own organisations. In overall, with many overlapping, simultaneous development processes going on at the platform, the vision of the platform objectives and benefits was seen as unarticulated. Either way, the interviewees' perceptions about value co-creation varied largely depending on their degree of activity in the ecosystem. According to most of the interviewees, more attention should be given to processes where something new is being created and experimented. In this context, the role of professionally and socially experienced facilitators was emphasisedand requested-in every other interview.

\section{Layer 3: Co-elevation of the worldviews and values with} (hidden) impacts on attitudes and behaviour

The more experienced the interviewees were at managing innovation hubs or the more they had been involved in co-creation in multidisciplinary settings according to their own descriptions of experience, the more they were sensible to predicting whether this service ecosystem would succeed in its objectives or not. That is, the expectations and levels of satisfaction regarding the value co-creating activities were rather different depending on their level of understanding the concept of value co-creation. For some of the interviewees, the Kampusareena platform represented a showroom for their already existing networks. To others, the noble objective of Kampusareena to become a world-class pioneer in university-industry collaboration and in applying the latest scientific knowledge in practice was considered as an accelerator to improve the understanding and practices of co-creation within their own organisations.

As some of the interviewees did point out, the investments on the value co-creating infrastructure had been huge. However, whether it had been worth it or not, was not so much up to the facilities provided by Kampusareena, but to the worldviews and values that direct the development of the value co-creation practices. Patience and longterm engagement is thus needed from all the actors participating in the service ecosystem. As we can though see from the results of layer 3 (see Table 5), when reflecting on the interviewees' worldviews and values in relation with their attitudes and behaviours towards the value co-creating practices, old habits stick hard and strong strategic guidance is needed to change them. More platform-specific facilitation and marketing are needed to support the service ecosystem development in more concrete ways. As the interviewees expressed, establishing new ways for working will not happen without facilitation and engagement. As such, the interviewees clearly indicated that more dialogue was needed to create a shared understanding of both the desired outcomes and the means through which those objectives could be obtained.

On the basis of the interviews, the biggest challenge at layer 3 was the missing interface between the two owners of the platform. The roles and responsibilities of these two main actors were more or less unclear for the interviewees, resulting in conflicting and confusing views about the objectives and means through which the platform activities should be developed. That includes the challenge of double-management, referred to as management by 'walking in two pairs of shoes'. As such, it strongly referred to the lack of shared strategic insight into what Kampusareena actually could and should represent to the university and its various stakeholders in the long run.

\section{Layer 4: Co-developing the underlying mind sets and concepts directing the service ecosystem development}

In order to identify the current mind sets and concepts as well as their impacts on how to direct the service ecosystem development in the long run, the results of layer 4 were largely mirrored against the results of the previous layers. In doing so, the data was interpreted according to the interviewees' levels of understanding and practicing (a) the ideas and concepts of systems dynamics and (b) the willingness for learning and renewal (see Table 6). That is, it was important to keep in mind that the autopoeitic nature of service ecosystems refers to a learning process, where balance and continuity between the four phases of value co-creation (co-experience, co-definition, co-elevation, co-development) is needed to genuinely build up a shared narrative for value co-creation.

In this study, the level of strategic visioning and planning did vary highly among the interviewees. As highlighted throughout the interviews, the self-organising and selfadjusting nature of value co-creation always comes back to people and the ways how the different structures and functionalities of the platform support the change. Still, 
Table 6 Results, Layer 4

\begin{tabular}{l} 
Co-developing the underlying mind sets and concepts directing the \\
service ecosystem development \\
\hline Systems dynamics \\
'It's not all about money. An intensive community is more important.' \\
(I-9) \\
'The particular aim in here is to enhance different forms of cross- and \\
transdisciplinary collaboration; to create systems dynamics from a \\
societal perspective.' (I-4) \\
'I have only been there to meet my existing partners and \\
stakeholders.' (I-3) \\
Renewal \\
'What is needed there is the unique concept of co-creation, \\
something that does not exist in many places.' (I-8) \\
'Before anything, we want to work here as a team regardless of \\
organisational boundaries.' (I-4) \\
'This is a learning process. The platform should be flexible but \\
durable. Co-creation - that creates the change.' (I-7) \\
'We are aiming for changes in the organisational culture.' (I-1) \\
'Literally, there is no such thing as an open environment - not as \\
long as we talk about money in this world.' (I-3) \\
Power of mind sets \\
'The platform builds on people and their random encounters, \\
together with the modes of operations, and the environment.' (I-5) \\
'There is nothing more important than motivation - motivation to \\
work hard and to adopt to changing conditions.' (I-1) \\
'In the end, it all depends on people.' (I-19) \\
\hline
\end{tabular}

although skilled and motivated to adopt the more systemic, S-D logical view on value co-creation, less than half of the interviewees proved to have no consistency in their responses. Although the found metaphors showed a very positive stand towards value co-creation, when examining the entire data in relation to all responses by individual interviewees, the non-systemic and suspicious attitudes towards collaboration and change were also present. For example, there were several individuals who expressed scepticism and conflicts related to value co-creation at layers 1 and 2 (see Tables 3 and 4) and did not provide any valuable data to be analysed at layers 3 and 4. For them, value co-creation simply presented a new method to share and transfer knowledge.

\section{Conclusions}

Even if more attention is paid to both the individual's and the organisation's abilities to adapt to continuous change [36], many companies still lack behind on strategies that embrace the importance of understanding the socially constructed narratives that direct the complex multi-actor networks. At the same time, the notions and concepts related to value co-creation are also evolving, with significant impacts on how we perceive and respond to collaboration [33]. More holistic and in-depth understanding is needed about the formation and development of complex value networks.

In this study, the aim was to identify and analyse the explicit and symbolic (inter)relationships between the different actors involved in the value co-creation processes-and to understand their impacts on the networkspecific innovation capabilities. In overall, the interviewees' responses included many positive attributes connected with value co-creation, such as interesting, modern, pioneering and experimental. However, the actual level of the value cocreation practices still remained rather non-existent, and the interviewees' perceptions and understanding of value co-creation varied significantly. On the basis of the layerspecific results (see Tables 3 to 6), two co-existing and consistent narratives were found to explain the level of the value co-creation potential in the studied service ecosystem.

\section{Two alternative futures}

As we can see in Fig. 1, the first narrative 'breaks barriers' in terms of representing an open system with a strong focus on disruption through the diversity of actors involved in it. That is, it describes co-creation as a process where active participation in the discussions and events results in increased levels of value propositions and value exchange, thus referring to the autopoeitic nature [72] of the service ecosystem. With a holistic view on innovativeness, the first narrative is built on the ideas of resilience [73] and continuous renewal [74]. The second narrative then describes the view on a 'control driven' closed system, with a focus on predefined partnerships and outcomes. The value propositions in that service ecosystem are more related to the controllable forms of substance-related networks and measurable outcomes than in the disruptive learning process. So, in this second narrative, value cocreation refers to something where individuals, teams or organisations with rather similar interests and expertise join together for mutual benefit, actualised through knowledge share and transfer.

Although the found narratives do not necessarily mirror the course of all individual interviews, this twofolded nature of the results is significantly supported by the layer-specific results. Indeed, the mind sets in these two narratives are very different. In S-D logic terms, the first narrative focuses on co-creation as a method and a process, whereas the second narrative is more interested in the outcomes. As such, the second narrative could be seen as a representation of the Goods-Dominant (G-D) logic view on things, thus referring to some of the interviewees' clearly mechanical perceptions of value as something separate from the value co-creation process. In doing so, value co-creation is only viewed as the method and means through which the execution of relatively fixed plans will be efficiently carried out, either through resource exchange within the already 


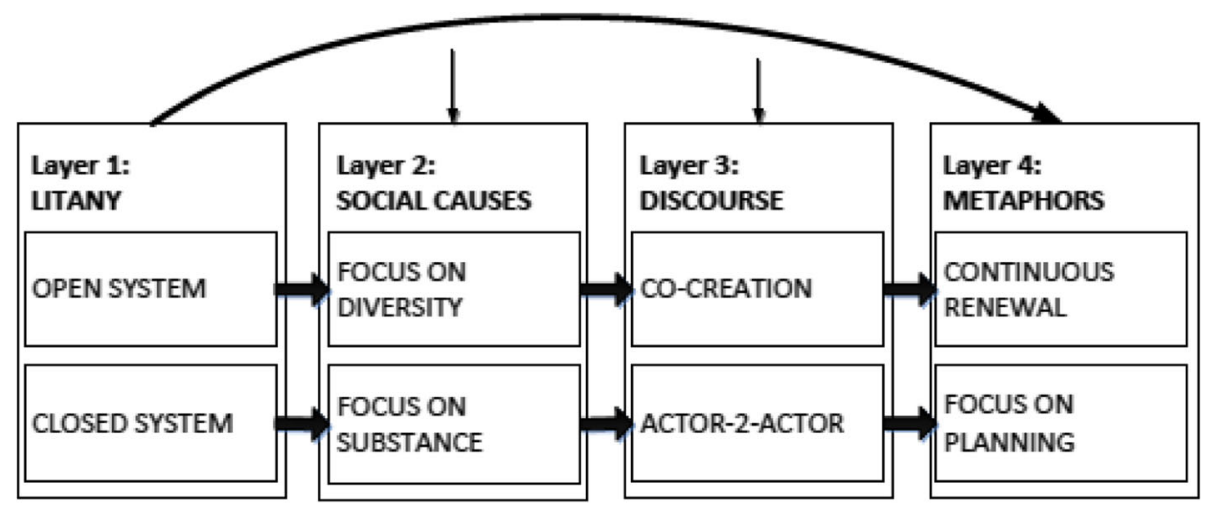

Fig. 1 Competing narratives

existing networks or through the integration of new resources by introducing new partnerships.

\section{Managerial implications}

The co-existence of the two narratives certainly reflects the initial phase of the studied service ecosystem. However, in order to avoid the further differentiation of the apparently divergent worldviews, more purposeful orchestration of the value networks is needed to incorporate these two narratives into a shared understanding of the service ecosystem's future directions. In fact, regardless the contextually changing nature and qualities of the self-adjusting service ecosystems, the following advice would most likely be useful for any service ecosystem under construction:

First, in order to foster the network-specific innovation capabilities, the ecosystem actors need to become engaged in co-experiencing and co-defining the service ecosystem. It is highly important that the ecosystem provides its members structures and functions that enhance casual meetings and interactions without a predefined agenda. Moreover, it is important to support any activities that bring together interest groups that would not easily come together otherwise-in this case, students, researchers and company representatives. It supports open communication and results in an increased level of willingness to share ideas and concepts among the ecosystem actors [75].

Second, open communication plays a crucial role in coelevating stimulating innovation. Therefore, the different visions and expectations considering the service ecosystem development should be thoroughly discussed (a) in an open environment where all the ecosystem actors are encouraged to take part and (b) in a way that helps the ecosystem actors to co-elevate their conflicting ideas and perceptions, and to integrate them with shared concepts and rules of conduct. Once all the visions, institutional rules and guidelines are openly and continuously shared, disrupted and coordinated, the benefits of the service ecosystem are more likely to emerge [75]. In other words, this study encourages managers to become active in ensuring that a common understanding of the visions and rules of the ecosystem are being developed. This requires supporting the institutional rules and guidelines. In this case study, the potential of interdisciplinary collaboration had not been fully realised, and many of the ecosystem actors had continued to follow their former routines and continued to work with their trusted partners from previous projects.

Third, whenever human networks are involved, it requires investments in facilitation. Although the service ecosystems view highlights the self-organising and selfadjusting nature of the networks, it still makes sense to allocate resources for the facilitation services. Trust and commitment develop slowly, yet they relate significantly to the functional abilities of the networks [75]. Instead, the question is more about understanding how to adopt the process of value co-creation in novel working environments. As indicated by the results of this case study, when the ecosystem actors had accessed to facilitation services, they were significantly more satisfied with the service ecosystem's functions in overall.

\section{Evaluation of the study}

Since the empirical data was collected only a year after the launch of the service ecosystem under evaluation, estimating its future success was neither the aim nor the result of this study. In addition, given the limited number of interviews in this study, it can be argued that the results are merely directional and might be partially intensified by many of the interviewees' pronounced expertise in innovation management. In addition, the high level of ambiguity in analysing the interviews, and the use of CLA proved to be somewhat susceptible for alternative interpretations. Yet, the intensified discussions enabled by the in-depth interviews and the fact that using CLA took the analysis to a completely new level compared to discourse analysis, most conventionally used for analysing the role of knowledge sharing and 
creation in qualitative research, approved to be especially useful in mapping the various dimensions of both the past and the present mind sets, attitudes and impressions towards value co-creation. In doing so, it was well in line with the S-D logical, i.e. the systemic approach of this study, and enabled creating an exceptionally indepth view on the current state and future prospects of the novel service ecosystem.

Given the growing interest on understanding the explicit and symbolic relationships and interrelations between the different value co-creating actors in the increasingly complex service systems, the results of this study offer significant new knowledge and understanding for all those interested in the service ecosystem development. In addition, it is highly recommended to further elaborate this unique combination where CLA is used to explore value co-creation in a real-life service ecosystem. Considering that there are many companies still lacking behind on strategies that embrace foresight and futures literacy [44], more attention should be paid to both the individual's and the organisation's abilities to adapt to continuous change [36].

\section{Author's contributions}

The author read and approved the final manuscript.

\section{Competing interests}

The authors declare that they have no competing interests.

\section{Publisher's Note}

Springer Nature remains neutral with regard to jurisdictional claims in published maps and institutional affiliations.

Received: 7 August 2017 Accepted: 13 March 2018

Published online: 17 May 2018

\section{References}

1. Kaplan AM, Haenlein M (2010) Users of the world, unite! The challenges and opportunities of social media. Bus Horiz 53:59-68

2. Singaraju SP, Nguyen QA, Niininen O, Sullivan-Mort G (2016) Social media and value co-creation in multi-stakeholder systems: a resource integration approach. Ind Mark Man 54:44-55

3. Hargittai E, Walejko G (2008) The participation divide: content creation and sharing in the digital age. Inf, Communic \& Soc 11:239-256

4. Akaka MA, Vargo SL (2014) Technology as an operant resource in service (eco)systems. Inf Syst and e-Bus Man 12:367-384

5. Senge PM (2006) The fifth discipline. The art \& practice of the learning organisation. Random House, London

6. Wilenius M (2014) Leadership in the sixth wave — excursions into the new paradigm of the Kondratieff cycle 2010-2050. Eur J of Fut Res 2:1-11

7. Kenney M, Zysman J (2016) The rise of the platform economy. Iss in Sci and Tech 32:61-69

8. Weber MH, Hine M (2015) Who inhabits a business ecosystem? The Technospecies as a unifying concept. Tech Inn Man Rev 5:31-44

9. Hirvonen P, Helander N (2001) Towards joint value creation processes in professional services. The TQM Mag 13:281-291

10. Maglio PP, Kieliszewski CA, Spohrer JC (2010) Handbook on ervice science, 1st edn. Springer Science \& Business Media, USA

11. Ramaswamy V, Ozcan K (2014) The co-creation paradigm. Stanford University Press, Redwood City

12. Vargo SL, Lusch RF (2014) Service-dominant logic: premises, perspectives, possibilities, 1st vol. Cambridge University Press, Cambridge
13. Frow P, Nenonen S, Payne A, Storbacka K (2015) Managing co-creation design: a strategic approach to innovation. British J of Man 26:463-483

14. Lusch RF, Vargo SL, Tanniru M (2010) Service, value networks and learning. J of the Acad Mark Sci 38:19-31

15. Palo T, Tähtinen J (2013) Networked business model development for emerging technology-based services. Ind Mark Man 42:773-782

16. Norman R (2001) Reframing business - when the map changes the landscape. John Wiley \& Sons Ltd, West Sussex, London

17. Vargo SL, Lusch RF (2016) Institutions and axioms: an extension and update of service-dominant logic. J of the Acad of Mark Sci 44:5-23

18. Maglio PP, Vargo SL, Caswell N, Spohrer J (2009) The service system is the basic abstraction of service science. Inf Syst and e-Bus Man 7:395-406

19. Ranjan KR, Read S (2016) Value co-creation: concept and measurement. J of the Acad of Mark Sci 44:290-315

20. Calvagno M, Dalli D (2014) Theory of value co-creation: a systematic literature review. Man Serv Quality 24:643-683

21. Senge PM (2006) The fifth discipline: the art \& practice of the learning organization. Doubleday, New York, USA

22. Cirella S, Canterino F, Guerci M, Shani RAB (2016) Organizational learning mechanisms and creative climate: insights from an Italian fashion design company (early view). Creat and Inn Man 25:211-222

23. Lozano R (2014) Creativity and organizational learning as means to foster sustainability. Sust Dev 22:205-216

24. Bergman JP, Jantunen A, Tarkiainen A (2015) Managerial cognition and dominant logic in innovation management: empirical study in media industry. Ind J of Bus Inn and Res 9:253-271

25. Vargo SL, Wieland H, Akaka MA (2015) Inn through institutionalization: a service ecosystem perspective. Ind Mark Man 44:63-72

26. Vargo SL, Akaka MA (2012) Value cocreation and service systems (re)formation: a service ecosystems view. Serv Sci 4:207-217

27. Barile S, Lusch R, Reynoso J, Saviano M, Spohrer J (2016) Systems, networks, and ecosystems in service research. J of Serv Man 27:619-651

28. Parkkinen I, Lehtimäki H (2015) Leveraging appreciative intelligence ${ }^{\bullet}$ for enhancing organisational change. Int J of Human Res Dev and Man 15:101-114

29. Stumpf SA, Doh JP, Clark KD (2002) Professional services firms in transition: challenges and opportunities for improving performance. Org Dynam 31:259-279

30. Kotter JP (2012) Accelerate! How the most innovative companies capitalize on today's rapid-fire strategic challenges and still make their numbers. Harv Bus Rev Nov 2012:45-58

31. Poutanen P (2016) Complexity and collaboration in creative group work. University of Helsinki, Helsinki

32. Elg M, Engström J, Witell L, Poksinska B (2012) Co-creation and learning in health-care service development. J of Serv Man 23:328-343

33. Aal K, Di Pietro L, Edvardsson B, Renzi MF, Guglielmetti Mugion R (2016) Inn in service ecosystems. J of Serv Man 27:619-651

34. Capra F, Luisi PL (2014) The systems view of life. A unifying vision. Cambridge University Press, Cambridge

35. Vargo SL, Lusch RF (2011) It's all B2B and beyond...: toward a systems perspective of the market. Ind Mark Man 40:181-187

36. Kane GC, Palmer D, Phillips AN, Kiron D, Buckley N (2017) Achieving digital maturity. Adapting your company to a changing world. MIT Sloan Man Rev no 59180

37. Inayatullah S (2005) Questioning the future: methods and tools for organisational and societal transformation. Tamkang University Press, Tamsui, Taiwan

38. Edmonson G, Valigra L, Kenward M, Hudson RL (2012) Making industryuniversity partnership work. Lessons from successful collaborations. Science Business Inn Board, AISBL, Brussels, Belgium

39. Bloedon RV, Stokes DR (2016) Making university/industry collaborative research succeed. Rese-Tech Man 37:44-48

40. Bharadwaj A, Sawy OA (2013) Digital business strategy: toward a next generation of insights. Special Issue: Digital Business Strategy 37:471-482

41. Edvardsson B, Tronvoll B, Gruber T (2011) Expanding understanding of service exchange and value co-creation: a social construction approach. J of the Acad of Mark Sci 39:327-339

42. Ojala A, Helander N (2014) Value creation and evolution of a value network: a longitudinal case study on a platform-as-a-service provider. In: Proceedings of 47th Hawaii international conference on system science, Hawaii

43. Jaakkola E, Helkkula A, Aaarikka-Stenroos L (2015) Service experience co-creation: conceptualization, implications, and future research directions. J of Serv Man 26:182-205 
44. Miller R (2015) Learning, the future, and complexity: an essay on the emergence of futures literacy. Eur J Educ 50:513-523

45. Maula M (2005) Organisations as learning systems. 'Living composition' as an enabling infrastructure. Elsevier, Amsterdam

46. Valkokari K (2015) Business, innovation, and knowledge ecosystems: how they differ and how to survive and thrive within them. Tech Inn Man Rev 5:17-24

47. Wieland H, Koskela-Huotari K, Vargo SL (2010) Extending actor participation in value creation: an institutional view. J of Str Mark 24:210-226

48. Ostrom AL et al (2010) Moving forward and making a difference: research priorities for the science of service. J of Serv Res 13:4-36

49. Gustafsson A et al (2015) Conducting service research that matters. J of Serv Mark 29:425-429

50. Vargo SL, Lusch RF (2004) Evolving to a new dominant logic for marketing J of Mark 68:1-17

51. Akgun AE, Keskin H, Byrne JC (2014) Complex adaptive systems theory and firm product innovativeness. J of Engin and Tech Man 31:21-42

52. Cai S, Yuan Q, Zhou P (2013) A resource mapping framework for value co- creation in social media. In WHICEB 2013 Proceedings, Wuhan, China

53. Vargo SL, Lusch RF (2017) Service-dominant logic 2025. Int J of Res in Mark 34:46-67

54. Kijima K, Arai Y (2016) Value co-creation process and value orchestration platform, global perspectives on service science: Japan. Springer, New York

55. Galbrun J, Kijima K (2009) Co-evolutionary perspective in medical technology: clinical innovation systems in Europe and in Japan. Asian J of Techn Inn 17:195-216

56. Kijima K, Rintamäki T, Mitronen L (2014) Value orchestration platform: model and strategies, annual conference of Japan Society for Management Information 2014, Niigata

57. Lusch RF, Nambisan S (2015) Service innovation: a service-dominant logic perspective. MIS Q 39:155-175

58. Vuori V, Helander N (2016) Knowledge barriers in university-industry knowledge networks. Presented at the 17th European Conference on Knowledge Management, Belfast, Northern Ireland

59. Adner R (2016) Navigating the leadership challenges of innovation. Sloan Man Rev 58:141-146

60. Perkmann $\mathrm{M}$ et al (2013) Academic engagement and commercialisation: a review of the literature on university-industry relations. Res Pol 42:423-442

61. Heger T, Boman M (2015) Networked foresight-the case of EIT ICT labs. Tech Forec and Soc Change 101:147-164

62. Jackson A (2016) Finland has one of the best education systems in the world - here are 4 things it does better than the US. Business Insider, http:// nordic.businessinsider.com/finland-has-one-of-the-best-education-systemsin-the-world\%2D-here-are-4-things-it-does-better-than-the-us-2016-11/ (Retrieved 1.7.2017)

63. World University Rankings (2017) Alliances in science. Innovation indicators, Times Higher Education

64. Kampusareena (2016) A new spark to campus life. http://www.tut.fi/en/ kampusareena/. Retrieved 1 July 2017.

65. Romero D, Molina A (2011) Collaborative networked organisations and customer communities: value co-creation and co-innovation in the networking era. J of Product Plann \& Contr 22:447-472

66. Siltaloppi J, Koskela-Huotari K, Vargo SL (2016) Institutional complexity as a driver for innovation in service ecosystems. Serv Sci 8:333-343

67. Inayatullah S, Milojevíc I (2015) CLA 20: transformative research in theory and practice. Tamkang University Press, Taipei, Taiwan

68. Milojevic I, Inayatullah S (2015) Narrative foresight. Fut 73:151-162

69. Inayatullah S, Izgarjan A, Kuusi O, Minkkinen M (2016) Metaphors in futures research. Fut 84:109-114

70. Inayatullah S (1998) Causal layered analysis poststructuralism as method. Fut 30:815-829

71. Vargo SL, Wieland H, Akaka MA (2015) Innovation through institutionalization: a service ecosystems perspective. Ind Mark Man 44:63-72

72. Riedy C (2008) An integral extension of causal layered analysis. Fut 40:150-159

73. Berkes F, Golding J (2003) Navigating socieal-ecological systems. Building resilience for complexity and change. Cambridge University Press, Cambridge

74. Sydänmaanlakka P (2017) Continuous renewal. The only way to survive. Pertec Consulting, Espoo

75. Koskela-Huotari K, Edvardsson B, Sörhammar D, Witell L (2016) Innovation in service ecosystems - breaking, making, and maintaining institutional rules of resource integration. J of Buss Res 69:2964-2971

\section{Submit your manuscript to a SpringerOpen ${ }^{\circ}$ journal and benefit from:}

- Convenient online submission

- Rigorous peer review

- Open access: articles freely available online

- High visibility within the field

Retaining the copyright to your article

Submit your next manuscript at $>$ springeropen.com 